\title{
NOTAS PARA UNA APROXIMACIÓN TEÓRICA A NUEVAS CULTURAS JUVENILES: LAS TRIBUS URBANAS
}

\author{
RAÚL ZARZURI CORTÉS*
}

DE UN TIEMPO A esta parte, han surgido en nuestro país una serie de cuestionamientos a ciertas manifestaciones juveniles que han venido paulatinamente asomándose y adquiriendo fuerza en nuestras urbes. No está demás decir, que estas manifestaciones han sido catalogadas como situaciones problemas que escapan al control normativo de la sociedad, por lo tanto, han sido objeto de cuestionamientos, como formas de expresión juvenil, identificándolas, como fuente de peligro y riesgo para el orden social, con la utilización de rótulos como delincuentes, drogadictos, jóvenes pandilleros, apáticos, entre otras cosas.

Estas miradas de la sociedad, como señala Barbero (1988) no estarían centradas en la preocupación "por las transformaciones y trastornos que la juventud está viviendo, sino más bien por su participación como agente de la inseguridad que vivimos». Entonces, todas las obsesiones del mundo adulto con los jóvenes, de corte moralista principalmente, denotarían la miopía y la hipocresía de la sociedad en que vivimos, que no es capaz de darse cuenta que el problema no está tanto en los jóvenes, sino en la sociedad que se ha construido, por lo

* Sociólogo, con estudios de Magíster en Antropología Universidad de Chile. Docente e Investigador Departamento de Sociología Universidad Cardenal Raúl Silva Henríquez. Docente Escuela de Sociología y Maestría en Ciencias Sociales Universidad ARCIS. 
tanto como lo señala el autor, «ellos están haciendo visible lo que desde hace tiempo se ha venido pudriendo en la familia, en la escuela, en la política». Son ellos los que están reconstruyendo y creando nuevos modelos societales, nuevos valores y solidaridades, construyendo nuevas subjetividades, en el fondo como diría «De Kiruza» perciben que «algo está pasando, algo huele mal», quizás no tengan claro el o los caminos a seguir, las propuestas, pero hay algo allá afuera, ciertas intuiciones que hay que considerar.

En ese sentido, lo que deberíamos preguntarnos, más que estigmatizar, caricaturizar o ridiculizar, es qué se esconde detrás de estas manifestaciones culturales de los jóvenes; qué nos quieren decir, cuestión que no es tan sencilla, ya que implica dar un giro en la mirada del observador, que tiene que dejar de lado, una mirada externa, donde esta mirada refleja una forma de interpretación constructora de una sola verdad y conocimiento, y pasar al punto de vista del observado, y tratar de comprender e interpretar desde este sujeto, las construcciones y significado que hacen de sus acciones, de su vida. En el fondo, situarnos en lo que Rossana Reguillo (1998) llama una epistemología del encantamiento donde se reconoce con respeto la condición y calidad de sujetos a los jóvenes y sus manifestaciones culturales, y abandonar una epistemología de la distancia.

En las próximas líneas, se pondrán en circulación algunos elementos que podrían ayudarnos a realizar un ejercicio más comprensivo sobre este nuevo tipo de manifestaciones culturales juveniles, de nuevas subjetividades y sociabilidades sacudiéndonos de ciertos marcos tradicionales para entender el fenómeno de las juventudes, los jóvenes y sus culturas, que actualmente se expresan en el fenómeno de las «tribus urbanas».

La aproximación que vamos a realizar obedece principalmente a ciertas intuiciones reflexivas en torno a la aparición de estas nuevas culturas, dentro de procesos complejos que está viviendo el mundo moderno y que ha llevado en palabras de Maffesoli (1988) a un proceso de tribalización de la sociedad moderna, donde podemos situar la aparición de estas denominadas «tribus urbanas» como nuevas expresiones de subjetividad. Por lo tanto, esta reflexión se enmarca dentro de los procesos de comprensión respecto de la emergencia de estas nuevas culturas, tan estigmatizadas y etiquetadas por el mundo oficial, adulto y moderno, como señalábamos anteriormente.

Las preguntas que vienen a rondar a estas nuevas realidades, apuntan a cuestiones relacionadas con la sociabilidad, entendida como 
la construcción de relaciones, redes, vínculos de amistad, entre individuos pertenecientes a un mismo grupo u organización. ¿Por qué aparecen? ¿qué los une? ¿qué hace que se nucleen y actúen como las antiguas tribus y clanes, construyendo de esta manera lazos y lealtades fuertes entre otras cosas, como las que podemos observar en estas agrupaciones? ¿qué nuevos modelos societales están en germen en estas manifestaciones?

Una posible respuesta al parecer, está en la búsqueda de afectos, ${ }^{1}$ de nuevos tipos de relaciones que dejen de lado las construcciones sobre las relaciones sociales realizadas por la modernidad, marcadas por la racionalidad o producto de la división del trabajo, que ha llevado a la perdida de éstos, en lo que hoy llamamos sociedad moderna. Ésta sería la gran crítica a la modernidad y una de sus características centrales, sobre las cuales se asienta lo postmoderno. En el fondo, la recuperación de lo que hemos perdido, —aunque no el sentido de la nostalgia de lo perdido - la vuelta a lo tribal, a lo afectivoemocional, propio de la comunidad, cuestión que se profundizará en los próximos párrafos.

La pregunta, que tendríamos que hacernos, es ¿cómo se puede explicar esta separación de lo afectivo y lo racional? Para responder esto, necesitamos remontarnos a la emergencia de la razón, que se constituye en un momento determinado de la historia, como el único discurso válido que puede darnos explicaciones objetivas y verdaderas sobre el mundo, dejando de lado y enviando a la periferia todo lo que sea subjetivo o irracional, como va a hacer el caso de las explicaciones religiosas, por ejemplo. Descartes en su famosa máxima «pienso luego existo» pone de manifiesto lo dicho anteriormente, la primacía de la mente, lo racional, sobre el cuerpo, los sentidos, los afectos, los sentimientos, etc.

Esto ha sido bastante trabajado desde la sociología. ${ }^{2}$ Uno de los «padres fundadores» de esta disciplina, Max Weber, al cual podemos catalogar como el gran reflexivo de la modernidad, señalaba que

1 Esta idea como hipótesis, ha sido trabajado inicialmente en conjunto con Rodrigo Ganter y aparece en el artículo: «Tribus urbanas: por el devenir cultural de nuevas sociabilidades juveniles», publicado en la Revista de Trabajo Social Perspectivas, año sexto, número 8, diciembre 1999. Universidad Católica Cardenal Raúl Silva Henríquez.

2 Habría que señalar en este punto, a pesar que no los trataré, a Tönnies uno de los sociólogos más olvidados y Simmel, que estudian el fenómeno de la modernidad. 
lo que caracteriza a la sociedad moderna es el proceso de racionalización que se da en ésta, o sea la razón como un todo único, la cual se manifiesta preferentemente, en la emergencia de la ciencia como única generadora de conocimiento, o como el gran metarelato, en conjunto con la aparición de la secularización, la burocracia y del capitalismo.

Otro distinguido sociólogo, Durkheim, nos señala que estos procesos de racionalidad asociados a los procesos de industrialización, han provocado que las relaciones de sociabilidad se vean afectadas, trastocadas y transformadas, lo cual ha socavado a la comunidad, reemplazándola por la sociedad. Entonces asistimos al desplazamiento de formas de relaciones sociales más afectivas, cara a cara, que integran al individuo a la comunidad a partir de lo que Durkheim ha llamado solidaridad mecánica (integración por similitud), a formas de relaciones sociales marcadas por procesos de individualidad y donde el individuo se integra por necesidades gestadas por las diferencias de funciones que cumple cada uno al interior de la sociedad, lo cual genera interdependencia entre éstos, en lo que Durkheim llamaba solidaridad orgánica (integración por diferencia). Este proceso conduce necesariamente a la construcción de un hombre donde prima la autonomía individual, por sobre lo comunitario.

De esta forma la modernidad y por ende la sociedad moderna, no sólo es racional sino que también se le puede sumar la característica de funcional, abandonando todo lo que se aparta de esto, en este caso, lo afectivo, lo táctil, el cuerpo, entre otras cosas.

Se puede señalar a partir de esto, que la modernidad ha provocado la desintegración de la comunidad y una ruptura de las relaciones primarias; los espacios culturales locales sufren los embates de la globalidad desestabilizándose antiguas formas establecidas de identidad y cultura, siendo reemplazadas por espacios culturales nuevos y distintos; espacios que tienen la característica de ser globales.

La pregunta que surge entonces es, ¿cómo reconstruyen la comunidad, las relaciones primarias y la identidad (entre otras cosas) los jóvenes que pertenecen o se nuclean alrededor de lo que se ha denominado tribus urbanas?

La intuición que emerge como respuesta, resulta de una paradoja. La idea de la modernidad asimilada a la aldea global, del predomino de una sola cultura, en el fondo, de una cultura hegemónica, encuentra su respuesta en la aparición de microculturas o microsociedades; de nuevas sociedades primitivas —en el sentido durkheimniano de elementales - que empiezan a emerger en las grandes ciudades 
alterando el mapa urbano — en lo que la escuela etnográfica de Chicago llamara las zonas intersticiales de la ciudad-y el orden metropolitano. ${ }^{3}$ En el fondo, lo que se intentaba destruir (la variedad cultural) acaba reconstruyéndose o recreándose en nuevas formas de culturas urbanas, en algunos casos contestatarias y resistentes a la cultura dominante.

Estas microculturas, cuya expresión visible son lo que denominaremos tribus urbanas, comienzan a ser estudiadas allá por lo años 30, por lo que se ha llamado dentro de la tradición sociológica, la Escuela de Chicago o escuela de «ecología urbana», centrándose en temas, que en esa época eran considerados marginales como la delincuencia, la marginación social, la prostitución, las culturas juveniles (pandillas, bandas); temáticas que emergen en el nuevo ecosistema urbano de Chicago (Ganter y Zarzuri, 1999).

Sin embargo, antes de entrar de lleno en estas microculturas juveniles que aparecen en un mundo postmoderno, realizaré algunas referencias al concepto de culturas juveniles, en las que se insertan estas nuevas manifestaciones.

El concepto de culturas juveniles remite a dos conceptos centrales: cultura y juventud, los cuales como conceptos han tenido, tienen y van a seguir teniendo distintas definiciones, adquiriendo un carácter polisémico, que va a depender donde nos situemos a la hora de aventurar una definición.

Podemos partir señalando que lo que vamos a entender por jóvenes o juventud, es una categoría que ha sido construida socialmente y que encuentra su sentido en un espacio cultural determinado. Por lo tanto, esta es una construcción cultural, la cual como lo señala Walter Grob (1997), «no es una fase natural del desarrollo humano, sino una forma de comportamiento social que debe ser vista ante todo como un resultado de la cultura occidental y, consiguientemente, de la formación de la sociedad industrial moderna». Sin embargo, hay que considerar que esta construcción no sólo es resultado de la cultura y de la sociedad, sino que las distintas aproximaciones que tenemos al concepto, responden a las posiciones que adoptemos como observadores, a las distinciones que podemos realizar, y que obviamente se en-

3 Es lo que autores como Félix Guattari (1998) llamarán la «revolución molecular» en el contexto del Capitalismo Mundial Integrado, toda una amplia gama de pequeños grupos que entran en resonancia e interaccionan para resistir a las formas de representación dominantes. 
marcan dentro de los marcos culturales de la sociedad en que vivimos.

En este sentido, la juventud y el concepto de joven es una construcción moderna que tiene su origen sólo a partir de principios del siglo pasado en la época de la primera industrialización.

Realizar un rastreo de lo que se ha llamado joven(es) o juventud(es), en cuanto a imágenes que remiten a un concepto moderno, nos retrotrae hasta tiempos históricos más antiguos. Algunos autores como Carlos Feixa (1998) y G. Levi y J. Schmitt (1995) han podido encontrar pistas o interpretar el tiempo histórico en búsqueda de la juventud o los jóvenes a través de la construcción de modelos de juventud y que especialmente para Feixa, corresponden a ciertos tipos de sociedad. Siguiendo a este autor podemos encontrar los siguientes modelos de jóvenes asociados a determinadas sociedades:

\begin{tabular}{|c|c|}
\hline MODELO DE JUVENTUD & TIPO DE SOCIEDAD \\
\hline Púberes & Sociedades Antiguas \\
\hline Efebos & $\begin{array}{c}\text { Estados Antiguos } \\
\text { (Grecia y Roma) }\end{array}$ \\
\hline Mozos & $\begin{array}{c}\text { Sociedades Campesinas } \\
\text { Pre-industriales }\end{array}$ \\
\hline Muchachos & Primera Industrialización \\
\hline Jóvenes & Sociedades Modernas \\
& Post-industriales \\
\hline
\end{tabular}

Como se puede apreciar, el concepto de jóvenes recién aparece en las sociedades postmodernas industriales y asociado a ciertas manifestaciones culturales que comienzan a emerger durante los años cincuenta, especialmente en los Estados Unidos, de la mano del rock and roll, van a ir dando origen a lo que conocemos como cultura juvenil.

Siguiendo a Pérez Isla (1998:49ss), las relaciones sobre juventud y cultura han estado centradas en tres enfoques, los cuales se consideran centrales al momento de articular estos conceptos.

El primer enfoque está asociado a la Escuela de Chicago, que se va a interesar en las transformaciones que está sufriendo la ciudad producto de la modernización industrial. Aparece de esta manera, el concepto de subcultura juvenil, cuestión que posteriormente va a ser retomada por la escuela de estudios culturales. Autores como Foot White, Trasher, trabajaron las bandas como subculturas juveniles que empiezan a proliferar en los espacios intersticiales de la ciudad. 
Un segundo enfoque surgirá a mediados de los años cincuenta asociado con el rock, el cual se convertirá en el centro de una nueva cultura juvenil asociada a la música, la cual será asumida por las industrias culturales, la que paradojalmente permitirá la emergencia de una cultura juvenil, centrada en el consumo.

Un tercer enfoque está relacionado con el concepto de contracultura juvenil, el cual fue utilizado por T. Roszak, destacándose la oposición de las culturas juveniles a la racionalidad propia de las sociedades modernas, las cuales van a cristalizar en una serie de movimientos a finales de los años setenta y principios de los setenta.

Por lo tanto, antes de estas manifestaciones, se puede señalar que no hay jóvenes que tengan una cultura propia, sino que se adscriben a los modelos culturales propios de la cultura parental. Se visten de la misma forma que los adultos, escuchan la misma música, adoptan una estética adulta aunque la edad los distancie en términos generacionales por ejemplo. De esta forma como lo señala Beatriz Sarlo (1994) «Bertold Brecht, nunca fue joven, ni Benjamin, ni Adorno, ni Roland Barthes... ni Frank Sinatra, Doris Day...» van a ser (o ser considerados) jóvenes en comparación con lo que vendría después en Elvis Presley, The Beatles, The Doors, por mencionar algunos. Es la aparición de la fiesta, la máscara, los territorios existenciales, la estética que se constituyen en rebeldía, en desafíos al mundo adulto.

De esta forma, cuando nos referimos a las culturas juveniles, tenemos que hacer referencia a la aparición de pequeños grupos o microsociedades juveniles, las cuales han adquirido cierto grado de autonomía del mundo adulto. Como señala Feixa (1998:84) «en un sentido amplio las culturas juveniles se refieren a la manera en que las experiencias sociales de los jóvenes son expresadas colectivamente mediante la construcción de estilos de vida distintivos, localizados en el tiempo libre, o en espacios intersticiales de la vida institucional». Estas expresiones no son todas iguales, homogéneas, sino que van variando en el tiempo, en la medida que éstas son construcciones que realizan los jóvenes, que reciben la influencia de varios estilos, constituyéndose en estilos propios individuales que van identificando a las distintas culturas juveniles.

El estilo se convierte en lo distintivo de las culturas juveniles. Este puede ser definido siguiendo a Feixa (1998:79) como la «manifestación simbólica de las culturas juveniles, expresadas en un conjunto más o menos coherente de elementos materiales e inmateriales que los jóvenes consideran representativos de su identidad como grupo». 
Estas manifestaciones simbólicas son producto del reordenamiento y recontextualización de los objetos y símbolos, lo que Levi-Strauss ha llamado el «bricolage», la forma en que los sujetos, en este caso los jóvenes, resignifican los símbolos u objetos, dándoles en muchos casos significados distintos de los originales. Véase por ejemplo la utilización de cruces por parte de ciertos grupos que cultivan el heavymetal, que los distinguen de las personas religiosas. Acá, no es que estos jóvenes se mofen del símbolo, sino que éste ha adquirido un nuevo significado.

Esto permite la construcción de estilos juveniles, los cuales están compuestos por una serie de elementos culturales, entre los cuales puede destacarse: a) el lenguaje, como forma de expresión oral distinta a la de los adultos. Los jóvenes realizan juegos lingüísticos e inversiones lingüísticas que marcan la diferencia con los otros; b) la música, y especialmente el rock, que se transformó en la primera música generacional, distingue a los jóvenes, internalizándose en el imaginario cultural juvenil, y marcando las identidades grupales, producto de su consumo o de la creación; y, c) la estética que identifica a los estilos juveniles, marcados por ejemplo, por el pelo, la ropa, accesorios, entre otros.

Nos encontramos con producciones culturales, que se construyen a partir de revistas, murales, graffitis, tatuajes, videos, músicas. Estas producciones cumplen la función de reafirmar las fronteras del grupo y también de promover el diálogo con otras instancias sociales juveniles (Feixa, 1998:103).

Es a partir de estos elementos, que se puede hablar de una diferenciación del mundo juvenil del mundo adulto, lo cual ha sido tratado por algunos autores bajo la clave de ruptura generacional.

Quizás uno de los textos más lucidos que nos habla de esta situación, es el texto de Margaret Mead escrito a finales de los años sesenta, Cultura y compromiso, estudio sobre la ruptura generacional (1970). En este texto, la autora va a dar cuenta del cambio generacional producido en la sociedad moderna. De esta forma señalará la ruptura que se ha producido entre las generaciones adultas y las generaciones jóvenes.

Ella señala que los adultos no comprenden el cambio que está viviendo la actual sociedad, refiriéndose principalmente a la emergencia de la revolución electrónica que involucra el paso de una cultura lectora a una cultura de los medios: «nuestro pensamiento nos ata todavía al pasado, al mundo tal como existía en la época de nuestra 
infancia y nuestra juventud. Nacidos y criados antes de la revolución electrónica, la mayoría de nosotros no entiende lo que esto significa».

Para Mead los jóvenes, que ella llama jóvenes de una nueva generación «se asemejan más a aquellos jóvenes de la primera generación nacidos en un país nuevo». Dentro de este planteamiento, la autora señala que los jóvenes perciben que el discurso que se ha instalado en la sociedad, que dice que los jóvenes son el futuro, ya no puede ser sostenido. Para ellos - los jóvenes - el futuro es ahora, por lo tanto, lo hay que hacer es reubicar el futuro y dejar de lado las concepciones de futuro que se construyen en las culturas occidentales modernas y asumir ciertas concepciones de ciertas culturas no occidentales: «A juicio de los occidentales el futuro está delante de nosotros, quizás a sólo unas pocas distancias, pero siempre delante, aún no aquí fuera de nuestro alcance. A juicio de muchos pueblos de Oceanía el futuro reside atrás no delante». Esto misma idea se encuentra por ejemplo en la cultura aymará.

Por lo tanto señala la autora, «debemos ubicar el futuro como si fuera el niño nonato encerrado en el vientre de la madredentro de una comunidad de hombres, mujeres y niños, entre nosotros, como algo que está aquí, que ya está listo para que lo alimentemos y lo ayudemos y lo protejamos, que ya necesita elementos que debemos preparar antes que nazca, porque de lo contrario será demasiado tarde».

El llamado que hace M. Mead es claro, los jóvenes son los que encabezan el cambio cultural, el cambio de época que se está realizando y que involucra el paso de una sociedad a otra, por lo tanto serían los más indicados para guiar a otros. El desafío es aprender de ellos y con ellos como dar los pasos en este nuevo escenario, aunque como lo señala la autora «los jóvenes no saben qué es lo que se debe hacer, pero intuyen que debe haber un sistema mejor».

Entonces asistimos a la emergencia un nuevo tipo de cultura juvenil, una cultura que la autora llama cultura prefigurativa, la cultura de los hijos desconocidos, donde los adultos aprenden de los niños, realizando las distinciones con la cultura posfigurativa donde los niños aprenden primordialmente de los mayores y la cultura cofigurati$v a$, en la que tanto los niños y los adultos aprenden de sus pares.

Sin embargo hay que señalar que esta ruptura generacional, señalada por Mead, implica una disputa generacional. Si bien es cierto, y compartiendo el planteamiento de Mead, los jóvenes serían los más indicados para guiar a los otros en estos nuevos procesos cultura- 
les que están emergiendo. Sin embargo, se encuentran con un mundo adulto que no quiere ceder sus espacios de poder, que quiere mantenerlos a toda costa y por lo tanto, quieren mantener a estos recién llegados en un estado de juventud, que implica no ser aptos para tener responsabilidades, por lo tanto son irresponsables, y asimilan otras múltiples categorías peyorativas a esta condición, algunas de las cuales han sido enunciadas en anteriores párrafos.

\section{SOBRE LAS TRIBUS}

Aproximarse al concepto de Tribu Urbana no es sencillo, pero podemos señalar que en la literatura antropológica se utilizó con frecuencia la palabra tribu para designar a un «grupo autónomo, social y políticamente, de extensión definida, de homogeneidad cultural y organización social unificada que habita en un territorio que le pertenece» (Giner et al., 1998:898). En este sentido, la tribu remitía a lo "primitivo», a lo exótico, a lo antiguo, anteponiéndose a la sociedad, a lo civilizatorio, a lo moderno, asimilando de esta forma la tribu a pequeñas comunidades o clanes, los cuales eran descritos como grupos que estaban compuestos por fuertes lazos sociales, económicos, religiosos y de parentesco.

Hoy en día, el concepto se vuelve a utilizar pero asociado al ámbito urbano, a la ciudad, como en un espacio de proliferación de tribus urbanas compuestas preferentemente por jóvenes. Por lo tanto, se puede decir que el proceso de tribalización urbana que vive la sociedad es una cuestión moderna, asociada a los grandes cambios epocales y que se manifiesta preferentemente en las grandes urbes.

Una primera aproximación al concepto de Tribus Urbanas, la podemos encontrar si miramos a éstas como bandas, cuestión que puede ser rastreada teóricamente en lo que se denomina la Escuela Sociológica de Chicago.

Uno de los primeros intentos de esta escuela por sistematizar el conocimiento de estos grupos, proviene de Frederik Thrasher, quien en 1929 publica su libro The Gans. A Study of 1313 gans in Chicago, donde el autor pone de manifiesto, que estas agrupaciones «eran un sustituto para lo que la sociedad no logra dar... Las pandillas representan el esfuerzo espontáneo de los muchachos por crear una sociedad para sí mismos donde no existe nada adecuado a sus necesidades» (en Encinas Garza, 1994). 
A partir de este estudio sumados a los que realiza Whyte (1934) se descubre que las claves de estas agrupaciones se relacionan con la solidaridad interna que los une, lo que genera un fuerte sentimiento de lealtad, fundamentado en la ayuda mutua. Se constata que los jóvenes desarrollan profundos lazos afectivos que vienen desde su infancia, lo cual los lleva a considerar al grupo como su familia, y a la calle como su casa, lo que implica la vinculación a un territorio y la constitución de una tradición cultural distintiva como eje de agrupación. Junto con esto, Whyte, destaca que la naturaleza de estos grupos no es prioritariamente delictual, que critica la «miopía» de aquellos que etiquetaban a este tipo de jóvenes como desviados o anómicos.

Aproximaciones más modernas aplicarán el concepto de banda a agrupaciones de jóvenes que visten de forma similar y llamativa, y que poseen hábitos comunes y hasta lugares fijos de reunión. En estos agrupamientos se pueden encontrar modos de sentir y de pensar similares, y un soporte afectivo fuerte que ofrece a los miembros de estos grupos seguridad frente al mundo adulto.

Otros autores como García Canclini (1995) constatan la emergencia de estas agrupaciones asociadas al fenómeno de las construcciones de identidades en grandes ciudades. Para este autor, las bandas «compensan la atomización y la disgregación de las grandes urbes ofreciendo pertenencia a grupos; ante la pérdida de expectativas escolares y la estrechez del mercado de trabajo, brindan a decenas de miles de jóvenes otras formas de socialización y de acceso a bienes de consumo».

Por otra parte, Mario Margulis (1994) define las tribus como aquellos «receptáculos en los que se agrupan aquellos que se identifican como un look ampliado en el que entremezclan ropas, peinados, accesorios, gustos musicales, manera de hablar, lugares donde encontrarse, ídolos comunes, expectativas comunes, ilusiones compartidas. La tribu funciona como mecanismo de identificación de semejantes y de segregación de diferentes».

Michel Maffesoli (1988), será el primer sociólogo que diagnosticará este proceso de neotribalización en las sociedades de masa. Jesús Martín-Barbero señala que este autor «ha retomado la, sociológicamente desprestigiada, noción de masa para pensar justamente el correlato estructural del estallido y la reconfiguración de la socialidad en tribus».

Este fenómeno constituiría una respuesta al proceso de «desindividualización» consustancial a las sociedades de masas, cuya lógi- 
ca consiste en fortalecer el rol de cada persona al interior de estas agrupaciones, recuperando el carácter afectivo/emotivo a partir de una adhesión voluntaria.

Para este autor (en Ganter y Zarzuri, 1999), los rasgos básicos del proceso de neotribalización contemporáneo están asociados con los siguientes tópicos:

a) Comunidades emocionales: lo determinante de este elemento se vincula al carácter predominantemente afectivo/emotivo que se fragua al interior de estas agrupaciones, remodulando - frenando- el imperio de la racionalidad formal -instrumental, productiva y calculabilista - que predomina en la intemperie de las grandes metrópolis contemporáneas.

b) Energía subterránea: en este punto la inercia, la verticalidad y la uniformidad que caracteriza al continum de la sociedad actual se ve resquebrajado por una multiplicidad de léxicos — prácticas sociales polisémicas y alternativas- cuyo contenido se expresa a través de una grupalidad experiencial o un vitalismo que sitúa su flujo más allá del eje individualismo/muchedumbre.

c) Sociabilidad dispersa: bajo esta noción lo social emerge como un discurso omnipresente y que se expresa a través de relaciones contractuales urbanas entre individuos - mayoritariamente adultos- que comparten los patrones culturales y sociales definidos por el saber hegemónico (discurso apolíneo). Mientras que soterrada e intersticialmente se abre paso un discurso discontinuo y fragmentario (discurso dionisíaco) — expresión de un saber parcial— que se opone a la lógica dominante, asumiendo estrategias de interacción diversificantes que fundan una nueva socialidad neotribal. Lo interesante en esta reflexión es que ambos discursos intentarán medir inevitablemente sus fuerzas en algún tiempo y espacio determinado.

d) Fisicidad de la experiencia: el espacio físico — la urbe- se transforma aquí en un factor determinante en la conformación del entramado biográfico intersubjetivo. El espacio como artificio cultural que permite «formatear» la dimensión existencial del ser. Lo significativo aquí parece ser que a mayor globalización y cosmopolitismo metropolitano, mayor será el deseo de identificación espacial localista e intimista.

Intentando concluir, para Ganter y Zarzuri (1999) las tribus urbanas se pueden considerar como la expresión de prácticas sociales 
y culturales más soterradas, que de un modo u otro están dando cuenta de una época vertiginosa y en constante proceso de mutación cultural y recambio de sus imaginarios simbólicos. Proceso que incluso comienza a minar las categorías con las cuales cuentan las ciencias sociales para abordar la complejidad social, y que particularmente, en el caso de las nociones ligadas a la juventud, la realidad parece desbordar más rápidamente los conceptos con los que se trabaja.

También son la cristalización de tensiones, encrucijadas y ansiedades que atraviesan a la(s) juventud(es) contemporánea(s). Son la expresión de una crisis de sentido a la cual nos arroja la modernidad, pero también constituyen la manifestación de una disidencia cultural o una «resistencia» ante una sociedad desencantada por la globalización del proceso de racionalización, la masificación y la inercia que caracteriza la vida en las urbes hipertrofiadas de fin de milenio, donde todo parece correr en función del éxito personal y el consumismo alienante.

Por ultimo, como la instancia para intensificar la experiencia biográfica y la afectividad colectiva, el contacto humano y sobre todo la alternativa de construir identidad y potenciar una imagen social. En otras palabras, las Tribus Urbanas constituyen una posibilidad de recrear una nueva «socialidad», de reeditar un nuevo orden simbólico a partir del tejido social cotidiano.

En el fondo, la aparición de estas nuevas tribus o constitución de nuevas subjetividades vienen en palabras de Guattari, a reinventar y/o recomponer el tejido de solidaridades y los modos de vida devastados por la modernidad, lo cual sólo es posible de lograr mediante la aprehensión de territorios existenciales, cuestión que realizan estas nuevas tribus, pero con una estructura propia, como lo señala el autor. Este territorio existencial, está atrapado en una relación de caosmosis «es decir que hay un efecto de indiferenciación, de apropiación del todo, de todo lo que me rodea - el objeto amado, los objetos, mis ideas, mis sentimientos - y a partir de esa inmersión cáosmica, hay recomposición».

La observación de este nuevo fenómeno nos plantea nuevos desafíos para quienes estamos realizando investigación en este ámbito. Nos invita a utilizar los cuerpos teóricos de las ciencias sociales como cajas de herramientas (Guattari) que nos permitan afinar las miradas sobre los jóvenes y sus expresiones culturales, y no transformarlas en marcos rígidos, recetas como ha sucedido - y sucede - cuando hablamos de ellos. 
Esta es la propuesta que Francisco Zegers — siguiendo al autor- en su introducción al texto de Guattari, Cartografías del deseo (1989), señala que hay que transformar el cuerpo unitario de las ciencias sociales en un charco. «Es el charco de nuestro devenir-sapo, habilitados por fin a saltar de piedra en piedra, para catear entre las rendijas de las murallas académicas el enlace de una escena originaria».

Esto nos hace preguntarnos si ¿es posible aproximarse al fenómeno de las tribus urbanas y por tanto a la juventud, los jóvenes y las culturas juveniles a través de nuevos enfoques teóricos, que trasciendan las interpretaciones tradicionales que se han utilizado en nuestro país? y si esto es posible, ¿cuáles serían estos nuevos enfoques o nuevas aproximaciones teóricas que constituirían la base o soporte para estas nuevas interpretaciones, las cuales podrían revitalizar y desestigmatizar el fenómeno en cuestión posibilitando la deconstrución de las imágenes negativas que se tiene de los jóvenes y sus culturas?

SANTIAGO, JULIO DEL 2000

\section{BIBLIOGRAFÍA}

COSTA, P.; J. M. PÉREz y F. TROPEA (1997): Tribus urbanas. Barcelona: Paidós.

EnCINAS GARZA, JosÉ (1994): Bandas juveniles. México: Editorial Trillas.

GANTER, RODRIGO y RAÚL ZARZURI (1999): «Tribus urbanas: por el devenir cultural de nuevas sociabilidades juveniles». Revista de Trabajo Social Perspectivas No8. Santiago: Universidad Católica Cardenal Raúl Silva Henríquez.

GARCÍA CANCLINI, NÉSTOR (1995): Consumidores y ciudadanos. Conflictos multiculturales de la globalización. México: Editorial Grijalbo.

GINER, SALVADOR; EMILIO LAMO DE ESPINOZA y CRISTÓBAL TORRES (1998) (editores): Diccionario de sociología. Madrid: Alianza Editorial.

GROB, WALTER (1998): «Convertir el corazón de padres a hijos y el corazón de hijos a padres. El marco bíblico-teológico». En PETER HÜNERMANN y MARGIT ECKHOLT (editores): La ju- 
ventud latinoamericana en los procesos de globalización. Opción por los jóvenes. Buenos Aires: ICALA, FLACSO y EUDEBA.

GuATTARI, FÉLIX (1989): Cartografías del deseo. Santiago: Francisco Zegers.

(1998): El devenir de la subjetividad. Santiago: Dolmen Ediciones.

HOPENHAYN, MARTÍN (1993) «Nucleares, resistirse, abrirse: la tantas señales en la identidad juvenil». Revista Chilena de Temas Sociológicos, Año II, Nº3. Santiago: Universidad Católica Blas Cañas.

(1994): Ni apocalípticos ni integrados. Aventuras de la modernidad en América Latina. México: FCE.

HÜnermanN, Peter y MARGit ECKHOLt (1998) (editores): La juventud latinoamericana en los procesos de globalización. Opción por los jóvenes. Buenos Aires: ICALA, FLACSO y EUDEBA.

LAGOMARSINO, MARIO y RAÚL ZARZURI (1998): Televisión, espiritualidad y jóvenes. Santiago: CENECA.

MAFFESOLI, Michel (1990): El tiempo de las tribus. Barcelona: Icaria.

MARGULIS, MARIO (1996) (editor): La juventud es más que una palabra. Ensayos sobre cultura y juventud. Buenos Aires: Editorial Biblos.

_ los jóvenes en Buenos Aires. Buenos Aires: Espasa Calpe.

MARTÍN-BARBERO, JESÚS (1998): «Jóvenes: des-orden cultural y palimsestos de identidad». En HUMBERTO CUBIDES et al. (editores): Viviendo a toda. Jóvenes, territorios culturales y nuevas sensibilidades. Santafé de Bogotá: Universidad Central y Siglo del Hombre Editores.

MARTín CRIADO, ENRIQUe (1998): Producir la juventud. Madrid: Ediciones Istmo.

MEAD, MARgARET (1971): Cultura y compromiso. Estudio sobre la ruptura generacional. Buenos Aires: Granica.

PÉREZ ISLA, JosÉ (1998): «Una revisión sobre el vínculo de lo cultural y lo juvenil». En HUMBERTO CUBIDES et al. (editores): Viviendo a toda. Jóvenes, territorios culturales y nuevas sensibilidades. Santafé de Bogotá: Universidad Central y Siglo del Hombre Editores. 
REguiLLO, Rossana (1998): «El año dos mil, ética, política y estéticas: imaginarios, adscripciones y prácticas juveniles. Caso mexicano». En HUMBERTO CUBIDES et al. (editores): Viviendo a toda. Jóvenes, territorios culturales y nuevas sensibilidades. Santafé de Bogotá: Universidad Central y Siglo del Hombre Editores.

SARLO, BEATRIZ (1994): Escenas de la vida posmoderna. Intelectuales, arte y videocultura en la Argentina. Buenos Aires: Ariel. 